\title{
High Input Power Factor High Frequency Push-Pull DC/DC Converter
}

\author{
Sangita H. Deshmukh ${ }^{1}$, Afsana Sheikh ${ }^{2}$, Ms. Medha Giri ${ }^{3}$, Dr.D. R. Tutakne ${ }^{4}$ \\ ${ }^{I}$ Department of Electrical Engineering, Shri Ramdeobaba College of Engineering and Management Nagpur, \\ India 440013 \\ ${ }^{2}$ Assitant Prof.Department of Electrical Engineering, G H Raisoni COE, Nagpur \\ ${ }^{3}$ Assitant Prof, Department of Electrical Engineering, Rajiv Gandhi College of Engineering and Research, \\ RGCER, Nagpur \\ ${ }^{4}$ Professor, Department of Electrical Engineering, Rajiv Gandhi College of Engineering and Research, $G H$ \\ Raisoni COE ,Nagpur
}

\begin{abstract}
To maintain high efficiency and high power density increased switching frequency is the primary path. The push-pull converter used as ac-dc converter is very suitable for low and medium power application. High efficiency, low switching loss and high power density are the predominance of this application Increased switching frequency gives high power density, reduces size of components and this give simplicity of the circuit. Main aim of proposed topology is to obtain isolated dc voltage from ac voltage input with reduced switching losses and high input poer factor. This topology uses push-pull converter with z-source to improve input power factor and ,50 khz switching frequency with ferrite core transformer to obtain high poer density. This converter topology is suitable for obtaining low voltage, high current source from a high voltage, low current AC source. This would find application in high current battery bank charging, heating of the bearings, led lightings and charging of super capacitors and electrolysis with high current.
\end{abstract}

Keywords: ac to dc converter; high frequency push-pull converter; ferrite core transformer,z-source

\section{Introduction}

The rapidly expanding use of electronics in both commercial and consumer products, coupled with heightened awareness of the merits of energy efficiency in the power converter which nearly all of the products require has dramatically increased the demand for switching regulators. Unlike conventional dissipative series or shunt regulators in which the power regulating switch operates in continuous conduction mode, dissipating large amounts of power at high load currents - especially when the input-output voltage difference is large, the switching regulator has high efficiency under all input conditions. In switched mode power conversion, however the controlling device is almost an ideal switch which is either closed or open. By controlling the duty ratio of the switching pulses the output voltage can also be controlled in a very efficient way. Moreover, since the power semiconductor switch operates always at saturated or cut-off mode except for a brief transition between these two states, the switching regulator can achieve good regulation despite large variations in input voltage and load changes and the efficiency is maintained throughout.

Power electronic converters are widely used in many applications including renewable energy generation, industrial equipment/motor drives, electric vehicle/train, air-craft, household appliances, electronic ballasts, computer power supplies, power supplies for telecommunication equipment, etc. In the last decades, the scope of UPS has been increasing in the world due to increasing number of critical loads such as medical equipment; intensive care units need the continuous supply of high quality sinusoidal voltage. However UPS is large and bulky due to the use of main frequency. In low input voltage system, the conduction loss of switches becomes the main consideration. To overcome the disadvantages, a novel isolated push-pull, dc-dc converter with z-source was proposed.

Designers of dc-dc power converters are under relentless pressure to increase power density, efficiency, reliability, improve transient response, and reduce cost, preferably achieving all these goals simultaneously. In reality, certain goals are more important than others. For example, aerospace applications often have restrictions on overall system mass, and some loads require fast dynamic response. The use of switching frequencies is a promising approach to provide substantial gains in power density and bandwidth.

In the recent years, high-frequency power technology in both the sectors that is consumer and industries have developed more in all electricity power usage systems. However, specifically high frequency resonant inverters used for industrial and consumer appliances causes switching losses and conduction losses of power devices. The size as well as

High power density is an everlasting topic of power electronics. High frequency is an effective way to improve power density. In order to boost the switching frequency, the switching loss should be reduced at first. 
Moreover, due to the limited energy storage capability of batteries, the efficiency requirement for DC/DC converter in UPS systems will be high. Thus, the study on the push-pull converter has become more and more essential.

Power electronics has generated new horizons with regards to power conversion and control. There are several design patterns of switching regulators. The main purpose of the switching mode operation is to reduce the size of the isolating transformers and filter chokes and to increase the efficiency. Therefore the voltage of the ac mains is first rectified and applied to z-source to obtain high input power factor. Then this voltage is converted to a high-frequency ac voltage by an inverter. Fig.1.1 shows the block diagram of high power factor push-pull converter.

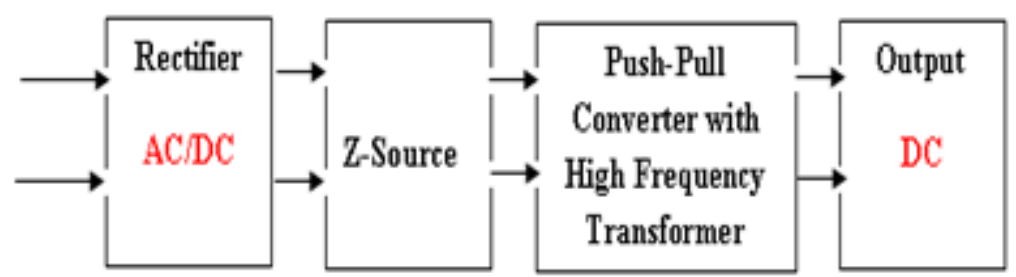

Fig 1.1 High Power Factor Push-Pull converter

The output of the inverter is transformed by a high frequency transformer to the desired voltage, then rectified and filtered. The control may be introduced at any stage the actual stage depends on the load requirements and the overall cost structure. The basic scheme is as shown in fig 1.1. Converters converting dc to dc type are referred as DC-DC Converter. The objective of this project is to design a low voltage converter and to obtain high input power factor. The circuit is present for conversion of voltage from high dc voltage to low de voltage. The configuration is achieved using a high frequency dc- dc push pull converter with z-source Due to simplified power stage and the application of pulse width modulation technique and ferrite core transformer a relatively smaller overall converter size is achieved. This project will explore the possibility of low cost power electronic interface ( $\mathrm{dc}-\mathrm{dc}$ converter). The input voltage to the push pull dc-dc circuit is 325 volts and the output voltage obtained is $24 \mathrm{~V}, 15 \mathrm{~A}$ dc. The current capability of converter can also be increased. The converter is aimed for low cost, high reliability and less losses. The circuit diagram of AC to DC convertor is in figure 1.2 .

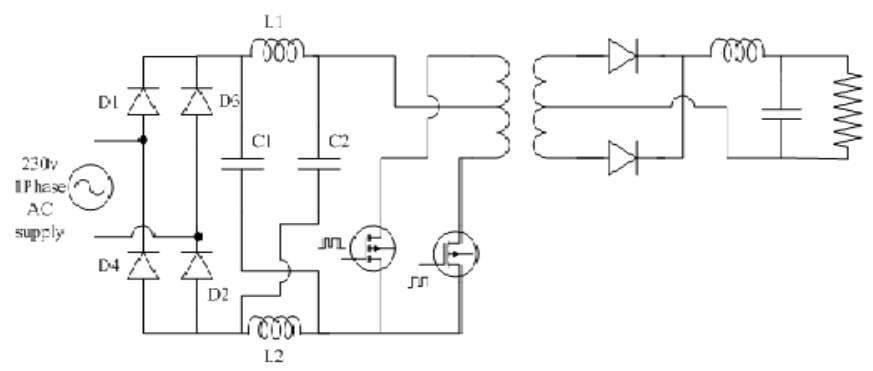

Fig.1.2 Circuit Diagram of high power factor DC/DC Push-Pull converter

A push-pull converter is a DC to DC converter; the DC power supply is changed by using a transformer. The transformation ratio is arbitrary but fixed; hence in most of the circuit implementation the duty cycle of the switches can be varied to vary the range of voltage ratios. The advantages of using push-pull converter with z-source are simplicity, high input power factor and ability to vary high power application, which leads to increased use in industrial DC power application.[6]

\section{Magnetization Characteristics of Push-Pull Converter}

The permeability of core material, $\mu$ is directly proportional to magnetizing inductance of primary winding. After saturation of the core $\left(\mathrm{B}_{\text {sat }}\right)$, magnetizing inductance decreases very fast. Therefore primary inductance of transformer reduces. The forward converter operates only in one quadrant of the B-H curve, moves upward the curve when the switch is on and resets during off period. Since there is no active reset the coercive falls to zero and the residual flux drops to the remanent flux, $B_{R}$ [1]. The advantage of push-pull convertor is that it works in two quadrants of the B-H curve, see-sawing back and forth as each primary is initiated. Specifically high frequency converters are used for high frequency applications which causes switching losses, conduction losses of power devices and decreases the evaluated capacity of power devices . This can be reduced by getting bigger cooling devices and warmth discharge systems. Furthermore ,conventional dc-dc converter with high frequency generates spikes in the input current which generates 
harmonics in the system. High frequency converters operated under hard switching PWM increases the levels of noise because of high frequency leakage current. Which leads to significant power losses as well as size and cost consideration for this power stage. In order to solve these practical issues, a novel technique of z-source, high switching frequency dc-dc push-pull converter with ferrite core circuit is developed.

\section{Proposed Scheme}

AC supply is power source of electric dc load. Need of transformation innovation that could change over ac to dc with high power factor for taking care of the demand of this dc load. $220 \mathrm{~V}, 50 \mathrm{~Hz}$ input supply is converted to dc voltage and current, then, this dc current is used for battery charging, electrolysis, led lightning ,etc. To convert AC supply to DC, and to obtain high input power factor power electronics devices are involved such as converter called rectifier, z-source, and push-pull converter. In the advancement of converters, they are worked to have estimation of effectiveness as high as could be expected under the circumstances, by minimizing losses of change utilizing switch. A battery charger that is lighter, smaller, high input power factor and efficient than conventional battery charger can be achieved by using high frequency dc to dc convertor (50Khz), highfrequency transformers (ferrite core), z-source and applying soft switching.

For higher power density, high switching frequency is required [4]. Now a days it is the need of the hour to achieve ac-dc power convertors with high power density, high efficiency and most importantly to maintain high input power factor, reliability, enhance transient response, and lessen cost, ideally accomplishing every one of these objectives at the same time. High power density is achieved by high switching frequency. Increased switching frequency causes switching losses, proximity, core losses in magnetic components and dielectric losses. Also increases in switching frequency expand cost and power loss with no attendant increment. The only distinct option for expanded energy density is lessening of the required measure of stored energy per working cycle. For a circuit processing a specified amount of power is accomplished by increasing the switching frequency. Simulation Results

\subsection{Modelling of Proposed Project Architecture}

AC mains voltage is first rectified and not filtered. Then this voltage is applied to z-source and then converted to a high-frequency ac voltage by using push-pull converter. The advantages of using push-pull converter are simplicity and ability to vary to high power application, which leads to increased use in industrial DC power application. The output of the inverter is transformed by a high frequency transformer to the desired voltage, then rectified and filtered.Table 3.1 gives the parameters used for simulation.

Table 3.1 Parameters used in Simulation

\begin{tabular}{|l|l|l|}
\hline Sr.no & Parameters & Values \\
\hline 1 & AC Voltage & $230 \mathrm{~V}$ \\
\hline 2 & Inductor $\mathrm{L}_{1}, \mathrm{~L}_{2}$ & $150 \mathrm{mH}$ \\
\hline 3 & Capacitor $\mathrm{C}_{1}, \mathrm{C}_{2}$ & $0.0022 \mathrm{~F}, 1000 \mathrm{~V}$ \\
\hline 4 & Resistance $\mathrm{R} 1$ & $10 \Omega$ \\
\hline 5 & Transformer input voltage(peak -peak) & $325 \mathrm{~V}$ \\
\hline 6 & Transformer output voltage (peak -peak) & $24 \mathrm{~V}$ \\
\hline 7 & Inductor $\mathrm{L}_{3}$ & $0.1 \mathrm{mH}$ \\
\hline 8 & Capacitor $\mathrm{C}_{3}$ & $0.01 \mathrm{~F}$ \\
\hline 9 & Resistive Load & $1.4 \Omega$ \\
\hline
\end{tabular}

\subsection{Simulated Model}

Fig. 3.2 shows the simulated architecture.

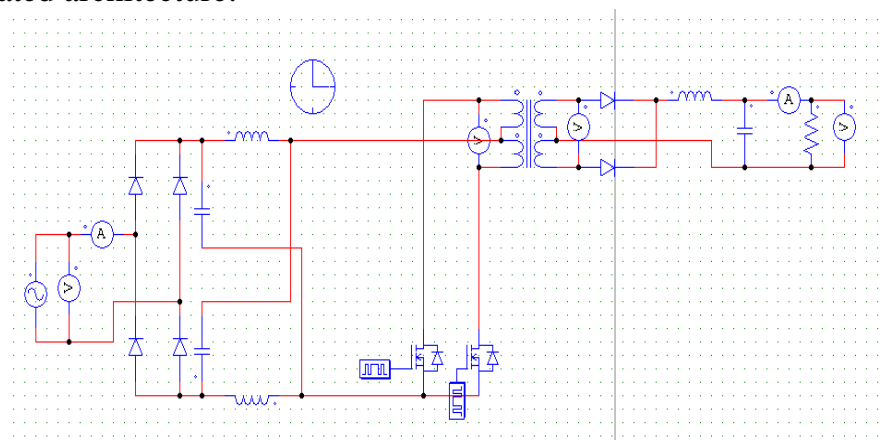

Fig. 3.2 Simulink Model of High Power Factor DC/DC Push-Pull Converter

\subsection{Simulation Results of Push-Pull Converter}


Fig. 3.3 shows the Pulse generation in simulation. Fig. 3.4 and Fig. 3.5 shows the Primary and secondary voltage and zoom view of primary and secondary voltage of transformer respectively.Fig.3.6 shows the DC Current waveform and DC voltage waveform across the load.fig 3.7 shows the transient response of this novel topology which shows that response of the system is very fast. Figure 3.8 shows the source current and source voltage and from the waveform it can be observed that source current and source voltage are almost in phase thus obtaining very high input power factor.

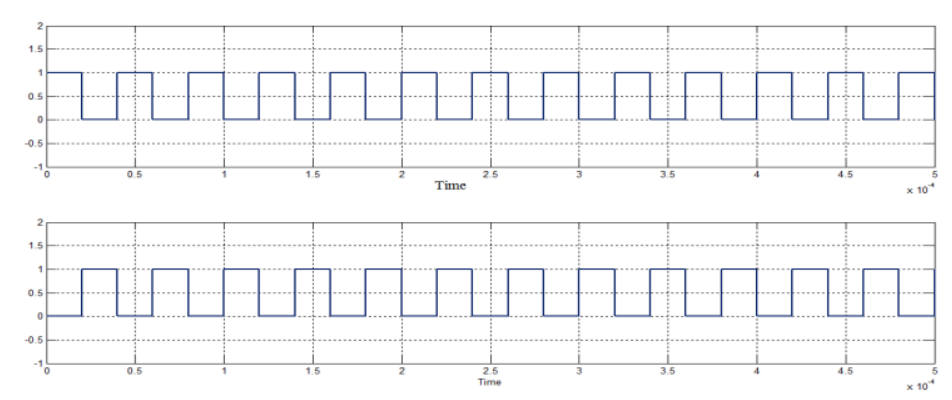

Fig. 3.3 Pulse generation in Simulation $(50 \mathrm{KHz})$

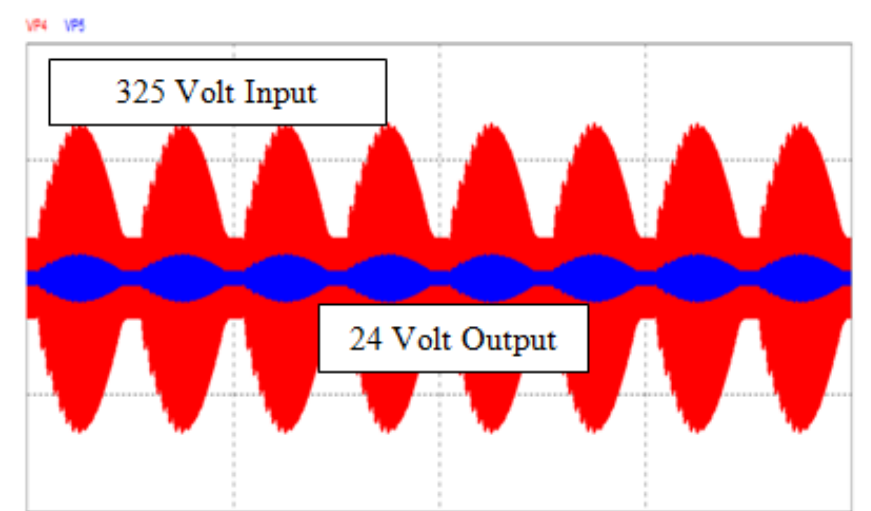

Fig. 3.4 Primary and Secondary Voltage of High Frequency Transformer

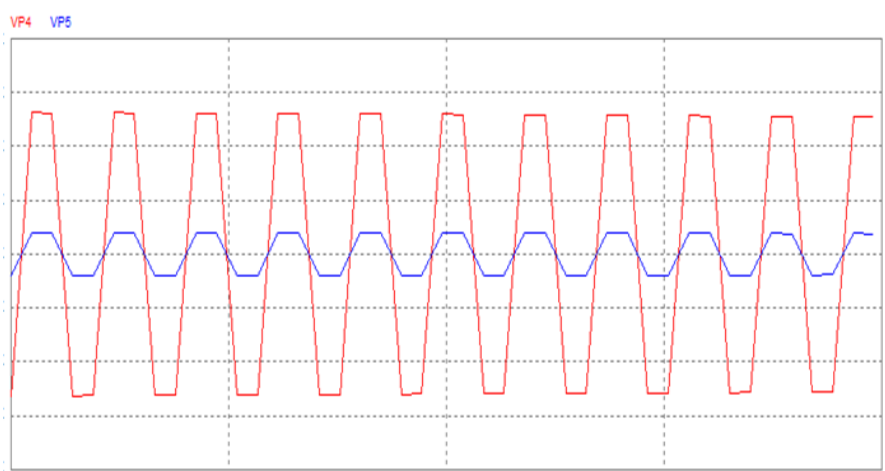

Fig. 3.5 Zoom view of Primary and Secondary Voltage of High Frequency transformer

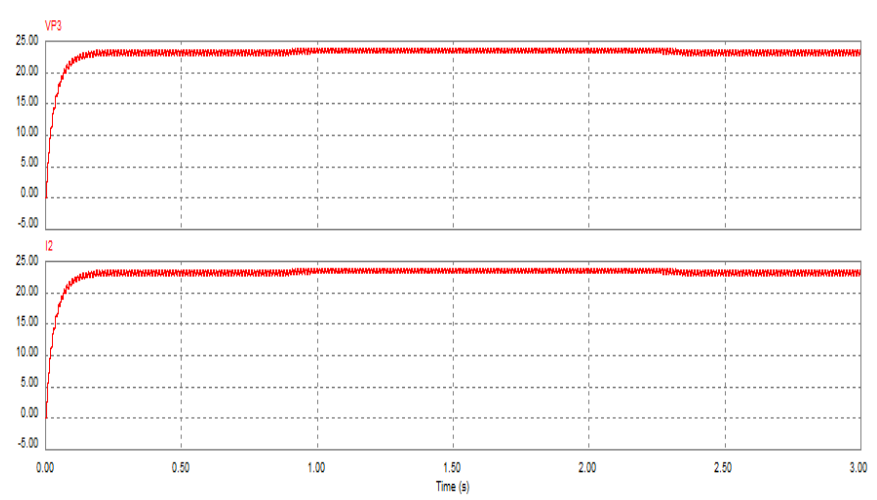


Fig. 3.6 DC Voltage and Current Waveform across the Load

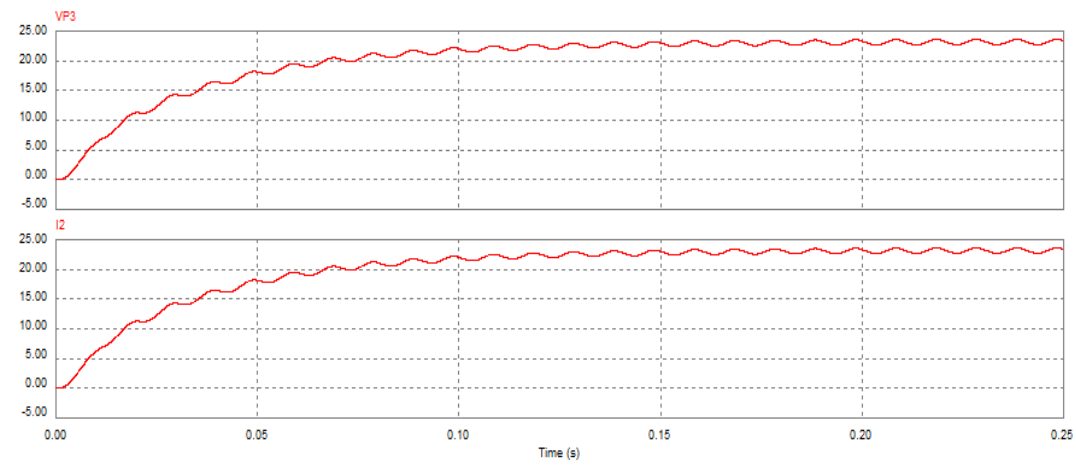

Fig 3.7 Transient Response during Startup of Proposed Convertor

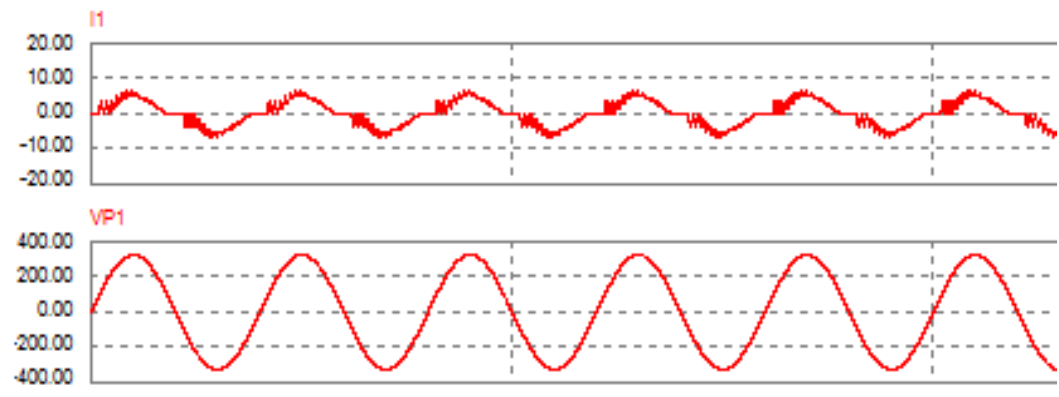

Fig 3.8 Source voltage and source Current with high power factor

So, from the simulation results, High input power factor, output low voltage and high current is achieved successfully. That means, the topology successfully worked in simulation.

\section{Ferrite Core Transformer}

The transformer designed is Ferrite core transformer.Ferrites have a significant advantage over other types of magnetic materials, viz., high electrical resistivity and low eddy current losses over wide frequency range. Additional characteristics such as high permeability and time/temperature characteristics have extended ferrite uses into quality filter circuits, high frequency transformers, wide band transformers, adjustable inductors, delay lines and other high frequency electronic circuits. It is comparatively cheap than other magnetic materials. For the most favorable combination of low cost, high Q, high stability and lowest volume, ferrites are the best core material choice for the frequency from $10 \mathrm{Khz}$ to $5 \mathrm{Mhz}$. Ferrite is a very suitable core material particularly for high frequency $(5 \mathrm{Khz}$ to $500 \mathrm{Khz})$ inverter power supplies. Ferrites may be used in saturating mode for low power $(<50 \mathrm{~W})$ and low frequency $(<10 \mathrm{Khz})$. They are used in fly-back transformers which offer low core cost at high voltage capability. Ferrite Cores have become an integral part of electronics manufacturing, particularly in products that generate a power supply or are designed for communication.

Made from Iron, Manganese and Zinc, ferrite cores are prized by manufacturers for their ability to filter digital signals so they don't pass interference to electronic devices. This is an especially important trait in switched mode power supply and radio frequency transformers and inductors. Their performance quality is the most significant factor in their usage, but ferrite cores also have a flexibility that allows them to be produced in a variety of shapes and sizes (including pot cores) without losing their high performance characteristics. They do not require a great deal of space to function. Stranded winding used in ferrite core have many merits such as it gives high accuracy in the frequency range, relatively low cost, able to control eddy current losses, skin effects are minimized etc.

\section{1 Core Magnetization}

Figure 4.15 shows the ideal magnetizing curve for a push-pull converter with $\mathrm{B}$ as the magnetic flux density and $\mathrm{H}$ as the magnetic field strength. When $\mathrm{S}_{1}$ conducts, the magnetic flux is pushed from $\mathrm{A}$ to $\mathrm{A}^{\prime}$. When $S_{2}$ conducts, the flux is pulled back from $A^{\prime}$ to $A$. The difference in flux, and thus in flux density, is proportional to the product of the primary voltage, $\mathrm{V}_{\mathrm{P}}$, and the time, $\mathrm{t}_{\mathrm{ON}}$, it is applied to the primary: $\mathrm{B} \approx\left(\mathrm{V}_{\mathrm{P}}\right.$. $\mathrm{t}_{\mathrm{ON}}$ ). 

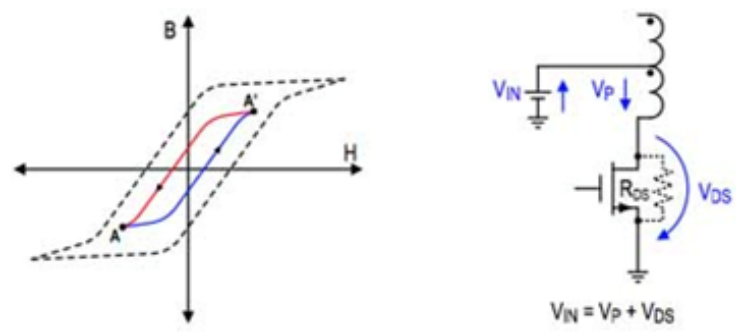

This volt-seconds (V-t) product is important as it determines the core magnetization during each switching cycle. If the V-t products of both phases are not identical, an imbalance in flux density swing results with an offset from the origin of the B-H curve. If balance is not restored, the offset increases with each following cycle and the transformer slowly creeps toward the saturation region.

\section{Conclusion}

Power electronic converters are widely used in many applications as follows:

- Charging of Super Capacitors ,

- For simultaneous Battery charging,

- For Electric Vehicles ,

- LED Lightings,

- Electrolysis and Electroplating

As UPS can handle critical loads, its demand is increasing worldwide. But it is large and bulky and injects lot of harmonics in the system due to use of main frequency. So, to overcome this disadvantage and to improve power density,to improve input power factor push-pull, dc-dc converter with z-source is proposed.

The proposed project simulation is carried out first in psim. The hardware is also designed to verify the simulation and experimental results.

Basically, this topology is to obtain low voltage $24 \mathrm{~V}$ and high current $15 \mathrm{~A}$ dc output with high input power factor by minimizing the losses and improving the performance of convertors and making the circuit as compact as possible by using push pull converter, ferrite core transformer and high switching frequency is an effective way to improve power density. If we change the duty ratio of PWM pulses variable output DC voltage can also be obtained. The obtained results showed that the proposed DC-DC converter represents a proper action and low voltage, high current and high input power factor is maintained. So basically, the benefits of push - pull DC/DC converter are:

- High input power factor with minimised source current

- Good Regulation

- Increased Efficiency

- $\quad$ Rugged, Reliable

\section{Acknowledgment}

Mrs S H deshmukh would like to extend her gratitude and thanks to Dr. M. M. Renge and Dr. S. B. Bodkhe for many precious discussions, creative ideas, motivation and support.

\section{References}

[1] S. Devikala1 P.Nirmalkumar2, "Experimental Verification of Soft Switching Push-Pull DC to DC Converter", International Conference on Power Electronics, Drives and Energy Systems December16-19, 2012.

[2] Imam Febriyandi, F. Danang Wijaya, Eka Firmansyah, "DC-DC converter as power supply of battery charger $100 \mathrm{~V} 300 \mathrm{~W}$ using $25 \mathrm{khz}$ switching frequency", IEEE Conference on Electrical Engineering and Computer Science 2014

[3] M.Ishitobi, S.Moisseev, L.Gamage, M.Nakaoka, D.Bessyo and H.Omori, "Pulse Width and Pulse Frequency Modulation Pattern Controlled ZVS Inverter v p e AC-DC Power Converter with Lowered Utility", IEEE 2002.

[4] John S. Glaser, Juan M. Rivas, “A 500 W Push-pull Dc-dc Power Converter with a 30 MHz Switching Frequency” IEEE 2010.

[5] Manu Jain, M. Daniele, and Praveen K. Jain, “A Bidirectional DC-DC Converter Topology for Low Power Application”, IEEE Transactions on power electronics, vol. 15, no. 4, July 2000

[6] H.Sugimura, A.M.Eid, S.K.Kwon, H.W.Lee, E.Hiraki, M, Nakaoka, "High frequency cyclo-converter using one-chip reverse blocking IGBT based bidirectional power switches", Proceedings of the Eighth International Conference on Electrical Machines and Systems (ICEMS), Vol.2, pp.1095-1100, 2005 